\title{
The Characteristics of Registered Sexual Offenders in an Australian Jurisdiction
}

\begin{abstract}
Current policies to manage convicted sexual offenders living in the community do not differentiate between those at different levels of risk. This is important if risk management strategies are to be better targeted. However, current methods of categorising risk bands rely on the application of data from other populations, and thus may lack validity when used in jurisdictions other than those in which the validation data were collected. This study provides a descriptive analysis of cases managed by police in one Australian jurisdiction, presenting the offence histories and risk profiles of this population. The analysis shows that the heterogeneity that exists in relation to offence type, level of risk, and victim characteristics, suggesting that more sophisticated systems of offender classification are likely to be required if judgements about risk are to inform offender management and the investigation of new sexual crime.
\end{abstract}

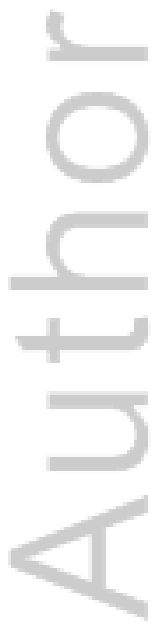

This is the author manuscript accepted for publication and has undergone full peer review but has not been through the copyediting, typesetting, pagination and proofreading process, which may lead to differences between this version and the Version of Record. Please cite this article as doi: 10.1002/jip.1461

This article is protected by copyright. All rights reserved. 


\section{Introduction}

The last 20 years have seen an increase in both the number of reported child sexual offences (Australian Institute of Criminology, 2005) and the number of people in Australia who have been convicted of these offences (Australian Bureau of Statistics [ABS] 2003; ABS 2015). Not only is the population of known sexual offenders living in the community now considerably larger than it has been in the past (Australian Bureau of Statistics, 2015), but changes in both the profile of offenders and the types of offence committed may have also occurred (e.g., Lin, \& Simon, 2016). For example, the development of the internet has increased access to illicit materials and resulted in more convictions for non-contact pornography offences than occurred twenty years ago. The way in which child sex offenders who live in the community are managed has also changed. Recent years have, for example, seen the initiation and expansion of numerous laws intended to manage the risk that known sexual offenders pose to public safety. These include sex offender registries and Sexually Violent Predator statutes in the US, Extended Supervision and Preventive Detention in New Zealand, and Extended Supervision schemes in Australia (see Doyle \& Ogloff, 2009; Mercado \& Ogloff, 2007; Petrunik, Murphy, \& Fedoroff, 2008; Vess \& Eccleston, 2009). Since the year 2000, each state and territory in Australia has introduced or amended legislation pertaining to the registration of sex offenders (Vess, Langskaill, Day, Powell, \& Graffam, 2011), with registrable offences including sexual offences committed against 
children (including sexual penetration, sexual relationship, indecent acts and recording), child pornography offences and, in some jurisdictions, other serious offences (such as infanticide, and the murder of a child). Registered offenders are required to provide information about their current and future contact with children, employment, club or group affiliations, details of their car, details of distinguishing features (including tattoos), details of inter-state and international travel, mobile and internet carriage provider information, and certain details around prior convictions. These developments have significantly improved the quality of data that is routinely collected about known offenders.

The legislation is based on the premise that sex offenders not only pose an especially grave and enduring risk to the safety of the public, but also that there is a high probability of repeat offending occurring against particularly vulnerable members of the community. Offender registries are thus seen to be based on perceptions by the public and lawmakers that sexual offenders pose an especially grave and enduring risk to the safety of the community, that there is a high probability of repeat offending against particularly vulnerable members of society, and that this risk can be effectively managed through the increased monitoring and supervision of known offenders (Applebaum, 2008; Levenson \& D’Amora, 2009; Vess, 2009; Zgoba, 2004). To be optimally effective, however, it has been argued that laws intended to improve public safety should apply the highest level of scrutiny to those offenders who pose the highest risk (Center for Sex Offender Management, 2008); the empirical literature has clearly established that not all sex offenders are at high risk for sexually reoffending, and, in fact, the largest group of offenders have relatively low rates of sexual recidivism (Doren, 2004; Hanson \& Thornton, 2000; Vess \& Skelton, 2010). And yet, 
blanket approaches such as Australian sex offender registries (which include all offenders with sexual convictions) neither differentiate between higher and lower risk offenders nor target the highest risk offenders for the most extensive intervention (see also Burchfield \& Mingus, 2008; Levenson \& Tewksbury, 2009; Mercado, Alvarez, \& Levenson, 2008; Levesnon, D’Amora, \& Hern, 2007; Logan, 2003; Tewksbury, 2005; Tewksbury \& Lees, 2006, 2009; Thomas, 2008).

Distinguishing between higher and lower risk groups of offenders is potentially not only useful in relation to effective supervision and monitoring, but also to the identification of persons of interest after new crimes have been reported. It makes sense, for example, to consider the whereabouts of offenders who have a demonstrated pattern and propensity for extra-familial child sexual offending when investigating new crimes where the identity of the perpetrator is unknown. A number of risk measures have been developed to assist with this task, with empirical evaluations showing that they can reliably classify risk in terms of different bands (see Hanson \& Morton-Bourgon, 2009; Langton et al., 2007; Smid, Kamphuis, Wever, \& Van Beek, 2014). However, the predictive validity of any risk assessment tool is ultimately determined by the data obtained from the specific offender population with which it is to be used. The use of risk assessment tools with other populations (i.e., the absence of local validation data) introduces uncertainty about the risk bands that are applied, as it is assumed that local population is equivalent to the one upon which the original validation was conducted (see Allan, Dawson \& Allan, 2006; Campbell, 2003; Craig, Beech \& Harkins, 2009; Falzer, 2013; Hanson \& Morton-Bourgon, 2009; Vess, 2008; Yang, Wong \& Coid, 2010). The initial aim of this study, then, is to describe the 
characteristics of a population of sexual offenders in one Australian jurisdiction in which local validation has yet to occur. Basic information about the offence history and risk profiles of registrants will be presented to highlight those characteristics that may be relevant to the identification of persons of interest, as well as to allow comparison with data from other populations upon which risk assessment tools have been validated.

Currently, relatively little is known about the profile of Australian sexual offenders or, indeed, the risks that they pose. International studies have, however, identified several factors that are empirically associated with higher rates of sexual re-offending across jurisdictions (Bengtson, 2008; Craig, Thornton, Beech \& Browne, 2007; Hanson \& Bussiere, 1998; Hanson \& Morton-Bourgon, 2005; Hanson, Thornton, Helmus, \& Babchishin, 2015; Hildebrand, de Ruiter, \& de Vogel, 2004; Smid, Kamphuis, Wever \& Van Beek, 2014; Tully Chou \& Browne, 2013). These include offender age and gender, having male victims, having multiple and extra-familial victims, and evidence of deviant arousal. It has, however, been suggested that various risk factors operate differently across cultural or ethnic groups (Allan, Dawson, \& Allan, 2006; Babchishin, Blais, \& Helmus, 2012; Långstrom, 2004; Smallbone \& Rallings, 2013), underscoring the importance of understanding the profile of the local offender population.

Perhaps the most significant piece of previous Australian work in this area was conducted by Smallbone and Wortley over fifteen years ago (Smallbone \& Wortley, 2000). They described the personal characteristics and offending patterns of 182 adult males who were, at the time, serving custodial sentences for sexual offences against children in the state of Queensland. These data were supplemented with offender self-report about 'modus 
operandi' collected from questionnaires, and a small number $(\mathrm{N}=16)$ of in-depth interviews. Their analysis considered differences between offender sub-types (intra-familial or those who had offended only within family settings; extra-familial, or those who had offended only outside family settings; and mixed-type offenders who had offended both within and outside family settings), demographic characteristics (including age, education, and ethnicity), offence history (including previous sexual and non-sexual convictions), psychosocial and psychosexual history (including their relationship with their parents and their experience of sexual victimisation), pornography use (child and adult), paraphilia's, networking with other child sexual offenders, and modus operandi (including victim characteristics, pre-, during and post-offence behaviours).

Smallbone and Wortley (2000) concluded that although Australian child sexual offenders are a heterogeneous group, over two-thirds of their sample had prior convictions (typically for non-sexual crimes). Their data also showed that some types of offenders (e.g., extra-familial) offenders were more likely to have multiple victims and, therefore, should be targeted in active investigations. The data presented in the current study is drawn from a more comprehensive and recent dataset, and thus offers some useful points of comparison in addition to providing a more contemporary profile of registered sexual offenders in Australia. This type of information can be usefully inform judgements concerning the application of certain risk assessment tools in the absence of local validation studies, which are both time consuming and expensive to conduct. 


\section{The Dataset}

The current dataset comprised cases provided by police in one Australian jurisdiction. It included demographic and offence history information obtained from police records as well as information reported by the offenders as part of the requirements of their registration. The dataset included offenders registered in the jurisdiction as a reportable offender (on the Australian National Child Offender Register; ANCOR) from 01 January 1998 to 30 June 2014, as well as all offenders legally considered to be 'dangerous' who had previously, or were currently, serving a sentence as at September $2013^{1}$. Dangerous offenders are persons who are considered to present an unacceptable risk that they would commit a serious sexual offence if they were not subject to a continuing detention or supervision order (The Dangerous Sexual Offenders Act [of Western Australia], 2006).

Offenders still in custody $(N=16)$, and offenders with no identified sexual offence were removed from the database $(N=42)$, resulting in the exclusion of 58 offenders. The final dataset included cases with sexual offences committed against adults, however each also had a conviction recorded of a child sexual offence or a reportable offence against a child. In the analysis below each 'case' refers to one offender, who had one or more convictions for sexual and non-sexual offences. Hereafter 'cases' are referred to as 'offenders' given that each had been found to be guilty of an offence. The final sample of 2,316 offenders were known to have collectively committed a total of 14,269 offences $(4,309$ sexual offences and 9,960 non-sexual offences).

\footnotetext{
${ }^{1}$ The dataset includes about $80 \%$ of all cases, which represents the number of cases for which it was possible to code. This is considered to be representative of the whole population.
} 
All offenders had convictions between 03/06/1959 and 04/12/2014 for offences committed between 01/01/1959 and 06/08/2014 ( $N=580$ missing offence date). The first recorded registration commenced on 02/10/1998 with the final case listed as 27/07/2015. Registered offenders who re-offend whilst on the register are required to report for life. The registration dates for two offenders were excluded, as the dates did not match (for one the date for registration preceded the offence date, and on the other the start and end dates for registration were the same).

\section{Results}

The results are presented in the order of demographic data about offenders, offence types (convictions, typology, and history), risk of re-offence, and victim characteristics. Where possible, data from Smallbone and Wortley (2000) are provided for comparison purposes. The sample sizes reported for each section of the results do not always match the total sample size (the missing data includes those who denied that any offence had been committed or who were categorised in the non-responders category by Smallbone and Wortley).

Sexual offence type

All sexual offences were classified using the Australian and New Zealand Standard Offence Classification (ANZSOC) $)^{2}$. Non-sexual offences were also classified according to ANZSOC, but grouped into broader categories of offending for ease of comparison. These

\footnotetext{
${ }^{2}$ previously known as the Australian National Classification of Offences when Smallbone and Wortley (2000) conducted their study.
}

This article is protected by copyright. All rights reserved. 
were property offences (e.g., theft), violent offences (e.g., physical assault) and any other offences (e.g., drug, traffic or weapon related offence). The type and proportion of sexual offences for the offenders' first and all sexual convictions are presented in Table 1, classified according to ANZSOC codes.
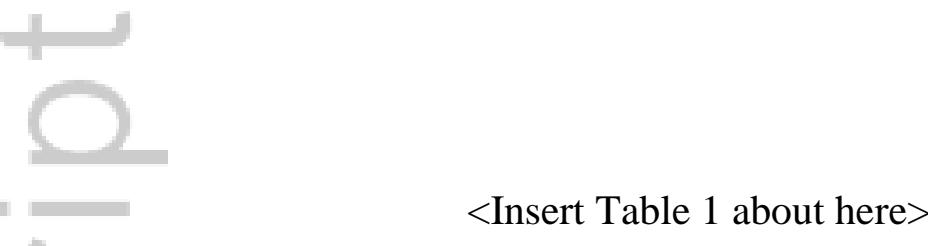

\section{Offender demographics}

Selected offender demographics, including age, gender, ethnic identification, and marital status, were considered first and are reported in Table 2 according to offender subtypes. Offender age was recorded at the time of the first sexual offence conviction ${ }^{3}$. Gender and ethnicity classifications were based on officially recorded data in relation to offence history for both samples. Marital status ratings were based on information recorded for the ANCOR register (i.e., self-report).

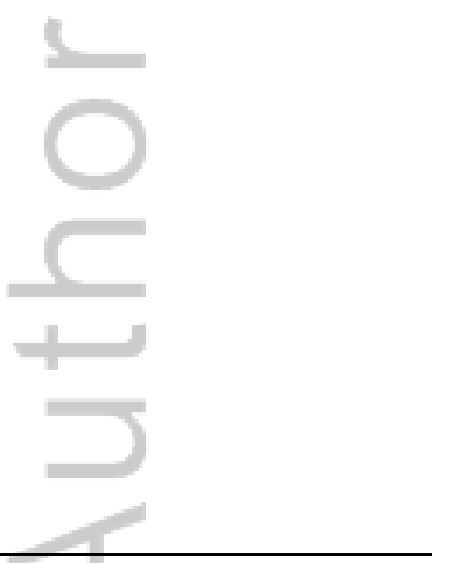

<Insert Table 2 about here>

\footnotetext{
${ }^{3}$ in Smallbone and Wortley (2000) age was recorded for their self-reported first sexual offence against a child (thus it may not have been an offence for which they were convicted).
} 


\section{Sub-types of offenders}

For the purposes of comparison, offenders were then classified into three distinct subtypes of offending, as defined by Smallbone and Wortley (2000): intra-familial offenders; extra-familial offenders; and mixed-type offenders. The sub-types of offending relate to the offenders' relationship to their victims, rather than the types of offence committed. In Smallbone and Wortley this classification was made on the basis of self-report data about the relationship with victims ${ }^{4}$, however in the current study this was determined by classifications based on the narratives of each offence recorded by police. The 'family setting' included children who were related to, or lived with, the offender. In the current study, an additional sub-type, 'pornography', was added for offenders with pornography offences only, and hence did not fit in the three categories defined by Smallbone and Wortley. A total 103 offenders could not be categorised due to missing victim details, and are not included in the table. The number and proportion of the offender sub-types is shown in Table 3 (below). This shows a higher proportion of extra-familial offenders, a lower proportion of intra-familial offenders, and a new type of offenders who have convictions for pornography offences in the current data set than was reported by Smallbone and Wortley.

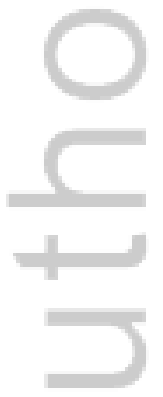

<Insert Table 3 about here>

\footnotetext{
${ }^{4}$ As a result of the data collection methods, the fourth group defined by Smallbone \& Wortley (2000), 'deniers' (those who continued to deny ever having committed a child sexual offence despite being convicted), could not be identified in this data.
} 


\title{
Risk level and Re-offending
}

The RM2000 (Helmus, Babchishin, \& Hanson, 2013) is routinely used to assess the likelihood of sexual re-offending. It classifies offenders based on likelihood of re-offending under four levels, 'low', 'medium', 'high' and 'very high' based on the first sexual offence conviction (which led to registration). In the current sample, $536(27.10 \%)$ offenders were classified as 'low' risk, 1,026 (51.80\%) as 'medium' risk, $309(15.60 \%)$ as 'high' risk, and $104(5.30 \%)$ as 'very high' risk. Although these risk bands have yet to empirically validated in this jurisdiction, this tool is routinely used by police to assess risk of re-offence on the assumption that similar risk factors will apply. A breakdown of risk according to offence type and offending sub-type group is provided in Table 4 below.

\author{
<Insert Table 4 about here>
}

Sexual re-offending following initial conviction and placement on the sexual offenders register was then examined. A total 181 offenders were recorded as having committed a sexual offence following conviction. Table 5 presents the number of reconvictions for sexual offences according to risk level.

<Insert Table 5 about here> 


\section{Victim Characteristics}

Data recorded about the offender's first sexual offence conviction was used to compare victim characteristics. Where multiple victims were involved in the first conviction, details relating to the first recorded victim were used ${ }^{5}$, including victim gender, age and relationship to the offender, and the number of victims. A total of $12 \%$ of victims were male, $72 \%$ were female, $16 \%$ were unknown (this incorporated victims of all sexual offence convictions). This differs from Smallbone and Wortley's (2000) data in that 52\% of victims were male and $48 \%$ were female (this included victims of all sexual offence convictions).

The average number of victims was $1.07(S D=0.46)$ for intra-familial offenders, 1.20 $(S D=0.53)$ for extra-familial offenders, $1.28(S D=0.51)$ for mixed type offenders and 1.48 $(S D=1.06)$ for pornography only offenders (based on convictions of sexual offences). In Smallbone and Wortley's (2000) data, intra-familial offenders had an average of 1.5 victims, extra-familial offenders had an average of 6.1 victims, and mixed type offenders had an average 20.0 victims (based on self-reports of all sexual offending).

Overall the number of victims for offenders in the current study ranged from zero to five victims, with a mean of 1.16 victims per offender $(S D=0.53)$. In comparison, Smallbone and Wortley (2000) reported that $47.3 \%$ of the mixed-type offenders had just one child victim, $16.4 \%$ had two child victims, less than $10 \%$ had more than 10 child victims, and two offenders reported more than 100 child victims (based on self-report data).

\footnotetext{
${ }^{5}$ Note: Smallbone and Wortley's (2000) data were based on a self-report of the offender's first sexual encounter with a child, thus it may not be an offence for which they were convicted.
} 
In terms of first victim age, $3.9 \%$ of children were aged under four years of age, $15.6 \%$ of victims were aged between 5 and 8 years of age, $58.0 \%$ of children were aged between 9 and 16 years of age, and the remaining 5.5\% were aged 17 or over. For Smallbone and Wortley (2000) $1.6 \%$ of children were aged under four years of age, $22.8 \%$ of victims were aged between 5 and 8 years of age, and $75.6 \%$ of children were aged between nine and 16 years of age. A minority of offenders $(14.70 \% ; N=52)$ had multiple victims recorded on the first offence. The number of second and subsequent victims was substantially smaller. Demographic details for each victim broken down by gender is provided in Table 6 below.

<Insert Table 6 about here>

Finally, the relationship of the offender to their first victim was compared across the offending sub-types for both the current study and Smallbone and Wortley (2000), see Table 7.

<Insert Table 7 about here>

\section{Discussion}

The primary aim of this study was to present descriptive data about a sample of Australian sexual offenders. A much larger, and contemporary, dataset was available for this 
purpose, following recent improvements in data collection methods associated with the implementation of the offender registration scheme. Descriptive data of this type, it is suggested, may be useful in the more focussed investigation of new crimes, as well as in developing tailored responses to offender supervision, management, and treatment. The data clearly illustrate the heterogeneity that exists within the population of sexual offenders in terms of offence type, level of risk, and victim characteristics. This is important in so far as it supports the arguments of criminal justice professionals that current registration laws are too generic and that greater flexibility through the creation of tiered systems of registration is required (see Day, Carson, \& Hobbs, 2014). A total of 536 (or 27\%) offenders in this sample were, for example, classified as 'low' risk using the assessment tool routinely used in this particular jurisdiction. Whilst we have suggested that such classifications have the potential to be unreliable, given that the validation sample used to develop cut-offs is from another jurisdiction, it is nonetheless apparent that the number of convictions for sexual re-offending in this group was very small. The risk assessment tool used in this jurisdiction, the Risk Matrix 2000 (RM2000) was developed from an earlier framework widely employed by prison, police, and probation services in the United Kingdom during the 1990s. A metaanalysis by Hanson and Morton-Bourgon (2009) reported that it had higher predictive validity than comparable measures, based on data from 6 studies although none of these were conducted in Australia.

This risk profile of this Australian population appears broadly consistent with that reported in the international research literature, including studies from North America, the UK, and New Zealand (Doren, 2004; Hanson \& Bussiere, 1998; Hanson \& Morton-Bourgon, 
2005; Hanson, Helmus, \& Thornton, 2010; Hanson \& Thornton, 2000; Skelton, Riley, Wales \& Vess, 2006). For example, based on a sample of 2,474 sexual offenders in New Zealand, Vess and Skelton (2010) reported sexual recidivism rates ranging from less than $7 \%$ for child victim, adult victim, and mixed victim offenders classified as 'low' risk, to between $35 \%$ and $39 \%$ for 'high' risk offenders, over an average follow-up period of 15 years. However, it is important to note, however, that the proportion of offenders who are designated as belonging to a certain risk category (e.g., 'low', 'medium' or 'high' risk) will depend upon the cut-off scores used to define these categories. Associated risk parameters (i.e., the observed rate of sexual re-offending for a given risk category) will therefore vary depending on where the category boundaries are set. Risk categories can be defined so that the designation of 'high' risk is reserved for relatively few offenders with a substantially higher observed rate of sexual re-offending, or conversely, the 'high' risk category can be defined by a lower threshold of re-offence risk, with a correspondingly large number of offenders included in this category. Ultimately, these designations involve a combination of empirical data and value judgements regarding what level of re-offending is to be considered high risk ${ }^{6}$.

There are also variations in observed risk levels based on sample characteristics. As noted earlier, certain risk factors (e.g., male victims, extra-familial victims) have been consistently associated with higher rates of sexual re-offending. The frequency and

\footnotetext{
${ }^{6}$ Some studies have created categories in which those designated as 'very high' risk have demonstrated sexual recidivism rates of over $50 \%$ during longer follow-up periods (Hanson \& Thornton, 2000). Others have designated high risk groups associated with lower rates of observed sexual recidivism, especially over shorter periods of observation (Barnett, Wakeling \& Howard, 2010; Bengtson, 2008). This suggests that the rate of relevant re-offending that has been observed for a given descriptive category should always be provided when assessing the risk posed in an individual case.
} 
distribution of these factors within a particular sample will influence the distribution of risk ratings for the sample. In order for a risk measure to provide valid inferences regarding risk for an individual offender, the normative samples by which the measure has been validated must include groups of offenders reasonably similar to the individual being assessed (Doren, 2002).

Comparison of the current sample with a smaller dataset collected over 15 years ago by Smallbone and Wortley (2000) shows that this jurisdiction manages a higher proportion of extra-familial offenders, a lower proportion of intra-familial offenders, and a new type of offenders who have convictions for pornography offences. A much smaller proportion of victims in this dataset were male ( $12 \%$ vs $52 \%)$, and more were female ( $72 \%$ vs $48 \%$ ) than were reported by Smallbone and Wortley, and the average number of victims lower for extrafamilial offenders (1.28 vs 6.1). Mixed offenders had an average of 1.48 victims, compared to the 20 victims reported by Smallbone and Wortley. Although the most common victim age was between 9 and 16 years, this was a smaller proportion in this data than the Smallbone and Wortley data (58\% vs $76 \%$ ). Whilst these differences may simply be a consequence of changes in detection and conviction practices over the last 15 years, it is important for investigators to have some sense of the types of offender who are placed on the register.

The main conclusion of this study is that the development and delivery of responses to sexual offending in Australia, and elsewhere, should be informed by a clear understanding of the nature of the population that is under consideration. Although the Smallbone and Wortley (2000) data were collected from a much smaller sample (and in a different jurisdiction), the data reported in this study implies that different responses are required. For example, 
Smallbone and Wortley's data could be taken as grounds for developing prevention interventions that focus more on protecting male, rather than female, victims. This is not supported by the current data, which also suggest the need to respond to the risk presented by the higher proportion of extra-familial offenders. In an area in which public policy is often fuelled by distorted portrayals in the media which stereotype all sex offenders as predatory and highly dangerous (Brayford \& Deering, 2012; La Fond, 2005; Nash, 2010; Terry \& Ackerman, 2009; Vess, 2006), data of this type should provide the foundation for determining the most effective responses.

Another important consideration concerns the use of standardised risk assessment tools in the identification of high risk offenders. There are now a number of risk assessment measures that have been empirically validated in different international jurisdictions, using a variety of offender samples. The use of actuarial risk instruments has become common practice in the assessment of risk. It is crucial to note, however, that the optimal use of such measures is only achieved when a specific risk measure has been validated on local offender populations, especially when these local populations include offenders who are racially or culturally different from those upon which a measure has been normed. Whilst this is a general limitation of all such measures, empirically derived assessment tools continue to provide the foundation of best practices in risk assessment. It also highlights the need for local empirical studies to validate each measure used locally to guide investigation procedures or to inform judicial decisions.

In relation to the investigation of sexual violence, this study suggests that empirically validated risk measures can be used to effectively identify a small subgroup of offenders who 
have a substantially higher risk of committing further sexual offences. These offenders can be identified by the presence of risk markers such as having male victims, having victims both within and outside of their family, and being of younger age. It is also important to note that a significant portion of sexual recidivism may represent crossover offending, i.e., offending against a different victim type than earlier sexual offences, although findings have been variable (Cann, Friendship, \& Gozna, 2007; Howard, Barnett \& Mann, 2014; Kleban, Chesin, Jeglic \& Mercado, 2012; Lin \& Simon, 2016; Stephens, Seto, Goodwill \& Cantor, 2016; Levenson, Becker, \& Morin, 2008; Sim \& Proeve, 2010). Offenders with a history of adult victims have been shown to be less consistent in their offending behaviour than those with a history of only child victims, with one study showing $37 \%$ of those who sexually reoffend doing so against child victims (Vess \& Skelton, 2010). Having victims of younger age has also been shown to increase the odds of having both male and female victims (Carlstedt, Nilsson, Hofvander, Brimse, Innala \& Anckarsater, 2009; Levenson, Becker \& Morin, 2008). Therefore, limiting an investigation to known offenders with similar victim types may miss a substantial portion of potential perpetrators. Another factor is age. Research has consistently shown that risk of sexual re-offending decreases substantially with age, especially in offenders over the age of 50 (Barbaree, Blanchard, \& Langton, 2003; Doren, 2006; Hanson, 2002; Skelton \& Vess, 2008; Wollert, Cramer, Waggoner, Skelton, \& Vess, 2010). However, there are a few individuals who have been observed to continue offending after the age of 70 . Thus whilst the risk of sexual offending decreases dramatically in older cohorts, it cannot be ruled out entirely. In cases such as this, individual patterns of prior offending behaviour provide the best guide for identifying high risk suspects. 


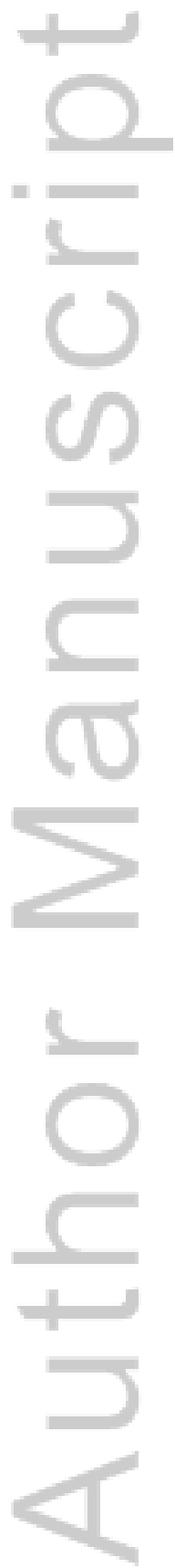

This article is protected by copyright. All rights reserved. 


\section{References}

Allan, A., Dawson, D., \& Allan, M.M. (2006). Prediction of the risk of male sexual reoffending in Australia. Australian Psychologist, 41, 60 - 68.

Appelbaum, P.S. (2008) Sex offenders in the community: Are current approaches counterproductive? Law \& Psychiatry, 59, $352-354$.

Australian Bureau of Statistics. (2003). Criminal Courts, Australia, 2001-02. Canberra, ACT: Author.

Australian Bureau of Statistics. (2015). Criminal Courts, Australia, 2013-14. Canberra, ACT: Author.

Australian Institute of Criminology. (2005). Trends in recorded sexual assault. Canberra, ACT: Author.

Babchishin, K.M., Blais, J., \& Helmus, L. (2012). Do static risk factors predict differently for Aboriginal sex offender? A multi-site comparison using the original and revised Static-99 and Static-2002 scales. Canadian Journal of Criminology and Criminal Justice, $\mathrm{xx}, 1-43$.

Barbaree, H. E., Blanchard, R., \& Langton, C.M. (2003). The development of sexual aggression through the life span: The effect of age on sexual arousal and recidivism among sex offenders. Annals of the New York Academy of Science, 989, 59 - 71.

Barnett, G.D., Wakeling, H.C., \& Howard, P.D. (2010). An examination of the predictive validity of the Risk Matrix 2000 in England and Wales. Sexual Abuse: A Journal of Research and Treatment, 22, $443-470$.

This article is protected by copyright. All rights reserved. 
Bartosh, D.L., Garby, T, Lewis, D., \& Gray, S. (2003). Differences in the predictive validity of actuarial risk assessments in relation to sex offender type. International Journal of Offender Therapy and Comparative Criminology, 47, 422 - 438.

Beech, A., Friendship, C., Erikson, M., \& Hanson, R.K. (2002). The relationship between static and dynamic risk factors and reconviction in a sample of U.K. child abusers. Sexual Abuse: A Journal of Research and Treatment, 14, 155_167.

Bengtson, S. (2008). Is newer better? A cross-validation of the Static-2002 and the Risk Matrix 2000 in a Danish sample of sexual offenders. Psychology, Crime \& Law, 14, $85-106$.

Brayford, J., \& Deering, J. (2012). Media influences on public perceptions of sex offenders: Impact on policy and practice. In J. Brayford, F. Cowe, \& J. Deering, (Eds.), Sex Offenders: Punish, Help, Change or Control? Theory, Policy and Practice Explored (pp. 52-68). New York: Routledge.

Burchfield, K.B., \& Mingus, W. (2008). Not in my neighborhood: Assessing registered sex offenders' experiences with local social capital and social control. Criminal Justice and Behavior, 35, $356-374$.

Campbell, T.W. (2003). Sex offenders and actuarial risk assessments: Ethical considerations. Behavioral Sciences and the Law, 21, 269 - 279.

Cann, J., Friendship, C., \& Gozna, L. (2007). Assessing crossover in a sample of sexual offenders with multiple victims. Legal and Criminological Psychology, 12, 149 - 163.

Carlstedt, A., Nilsson, T., Hofvander, B., Brimse, A., Innala, S., \& Anckarsater, H. (2009). Does victim age differentiate between perpetrators of sexual child abuse? A study of 
mental health, psychosocial circumstances, and crimes. Sexual Abuse: A Journal of Research and Treatment, 21, $442-454$.

Center for Sex Offender Management. (2008). The comprehensive approach to sex offender management. Retrieved 28/2/16 from

\section{http://www.csom.org/pubs/Comp_Approach_Brief.pdf}

Craig, L.A., Beech, A.R., \& Harkins, L. (2009). The predictive accuracy of risk factors and frameworks. In A.R. Beech, L.A. Craig \& K.D. Browne (Eds.) Assessment and treatment of sex offenders: A handbook (pp. 53 - 76). Chichester: Wiley-Blackwell.

Craig, L. A., Thornton, D., Beech, A., \& Browne, K. D. (2007). The relationship of statistical and psychological risk markers to sexual reconviction. Criminal Justice and Behavior, 34, 314329.

Craissati, J., \& Beech, A. (2004). The characteristics of a geographical sample of convicted rapists. Journal of Interpersonal Violence, 19, 371 - 388.

Day, A., Carson, E. \& Hobbs, G. (2014). Professional views on the management of sex offenders in the community, Journal of Offender Rehabilitation, 53, 171-189.

Doren, D.M. (2002). Evaluating sex offenders: A manual for civil commitments and beyond. Thousand Oaks, California: Sage.

Doren, D. M. (2004). Stability of the interpretative risk percentages for the RRASOR and Static-99. Sexual Abuse: A Journal of Research and Treatment, 16, 25 - 36.

Doren, D.M. (2006). What do we know about the effect of aging on recidivism risk for sexual offenders? Sexual Abuse: A Journal of Research and Treatment, 18, 137 - 157.

This article is protected by copyright. All rights reserved. 
Doyle, D.J., \& Ogloff, J.R.P. (2009). Calling the tune without the music: A psycho-legal analysis of Australia's post-sentence legislation. The Australian and New Zealand Journal of Criminology, 42, 179 - 303.

Falzer, P.R. (2013). Valuing Structured Professional Judgment: Predictive validity, decision-making, and the clinical-actuarial conflict. Behavioral Sciences and the Law, 31, 40 - 54.

Hanson, R. K. (2002). Recidivism and age: Follow-up data from 4,673 sexual offenders. Journal of Interpersonal Violence, 17, 1046 - 1062.

Hanson, R.K., \& Bussiere, M.T. (1998). Predicting relapse: A meta-analysis of sexual offender recidivism studies. Journal of Consulting and Clinical Psychology, 66, 348 362.

Hanson, R.K., Helmus, L., \& Thornton, D. (2010). Predicting recidivism amongst sexual offenders: A multi-site study of Static-2002. Law and Human Behavior, 34, 198 211.

Hanson, R. K., \& Morton-Bourgon, K. E. (2005). The characteristics of persistent sexual offenders: A meta-analysis of recidivism studies. Journal of Consulting and Clinical Psychology, 73, 1154-1163.

Hanson, R.K. \& Morton-Bourgon. (2009). The accuracy of recidivism risk assessments for sexual offenders: a meta-analysis of 118 prediction studies. Psychological Assessment, 21, $1-21$.

Hanson, R.K., \& Thornton, D. (2000). Improving risk assessments for sex offenders: A comparison of three actuarial scales. Law and Human Behavior, 24, 119 - 136.

Harris, A.J.R., \& Hanson, R.K. (2004). Sex offender recidivism: A simple question. (User 
Report 2004_03) Ottawa: Public Safety Canada Retrieved 20 February 2010 from http://www.publicsafety.gc.ca/res/cor/rep/2004-03-seoff-eng.aspx

Helmus, L., Babchishin, K. M., \& Hanson, R. K. (2013). The predictive accuracy of the Risk Matrix 2000: A meta-analysis. Sexual Offender Treatment, 8, 1-20.

Hildebrand, M., de Ruiter, C., \& de Vogel, V. (2004). Psychopathy and sexual deviance in treated rapists: Association with sexual and nonsexual recidivism. Sexual Abuse: A Journal of Research and Treatment, 16, 1 - 24.

Howard, P.D., Barnett, G.D., \& Mann, R.W. (2014). Specialization in and within sexual offending in England and Wales. Sexual Abuse: A Journal of Research and Treatment, 26, $225-251$.

Kleban, H., Chesin, M.S., Jeglic, E.L., \& Mercado, C.C. (2012). An exploration of crossover sexual offending. Sexual Abuse: A Journal of Research and Treatment, 25, 427 - 443.

La Fond, J. (2005). Preventing sexual violence: How society should cope with sex offenders.

Washington D.C.: American Psychological Association.

Langton, C.M., Barbaree, H.E., Seto, M.C., Peacock, E.J., Harkins, Leigh, \& Hanson, K.T. (2007). Actuarial assessment of risk for reoffense among adult sex offenders:

Evaluating the predictive accuracy of the Static-2002 and five other instruments.

Criminal Justice and Behavior, 34, 37 - 59.

Långstrom, N. (2004). Accuracy of actuarial procedures for assessment of sexual offender recidivism risk may vary across ethnicity. Sexual Abuse: A Journal of Research and Treatment, 16, 107-120.

This article is protected by copyright. All rights reserved. 
Levenson, J.S., Becker, J., \& Morin, J.W. (2008). The relationship between victim age and gender crossover among sex offenders. Sexual Abuse: A Journal of Research and Treatment, 20, $43-60$.

Levenson, J.S., \& D’Amora, D.A. (2007). Social policies designed to prevent sexual violence: The emperor's new clothes? Criminal Justice Policy Review, 18, 168 - 199.

Levenson, J. S., D’Amora, D.A., \& Hern, A.L. (2007). Megan's Law and its impact on community re-entry for sex offenders. Behavioral Sciences and the Law, 25, 587 602.

Levenson, J., \& Tewksbury, R. (2009). Collateral damage: Family members of registered sex offenders. American Journal of Criminal Justice, 34, 54 - 68.

Lin, J., \& Simon, W. (2016). Examining specialization among sex offender released from prison. Sexual Abuse: A Journal of Research and Treatment, 28, 253 - 267.

Logan, W.A. (2003). Sex offender registration and community notification: Emerging legal and research issues. Annals of the New York Academy of Sciences, 989, 337 - 351. Mercado, C.C., Alvarez, S., \& Levenson, J. (2008). The impact of specialized sex offender legislation on community reentry. Sexual Abuse: A Journal of Research and Treatment, 20, $188-205$.

Mercado, C.C., \& Ogloff, J.R.P. (2007). Risk and preventive detention of sex offenders in Australia and the United States. International Journal of Law and Psychiatry, 30, 49 59.

Nash, M. (2010). The politics of public protection. In M. Nash \& A. Williams (Eds.), Handbook of Public Protection, (pp. 60 - 80). New York: Willan. 
Petrunik, M., Murphy, L., and Fedoroff, J.P., 2008. American and Canadian approaches to sex offenders: a study of the politics of dangerousness. Federal Sentencing Reporter, $21(2), 111 \_123$.

Sim, D.J., \& Proeve, M. (2010). Crossover and stability of victim type in child molesters. Legal and Criminological Psychology, 15, 401 - 413.

Skelton, A., Riley, D., Wales, D., \& Vess, J. (2006). Assessing risk for sexual offenders in New Zealand: Development and validation of a computer scored risk measure. Journal of Sexual Aggression, 12, 277 - 286.

Skelton, A., \& Vess, J. (2008). Risk of sexual recidivism as a function of age and actuarial risk. Journal of Sexual Aggression, 14, 199 - 209.

Smallbone, S., \& Rallings, M. (2013). Short-term predictive validity of the Static-99 and Static-99-R for Indigenous and Nonindigenous Australian sexual offenders. Sexual Abuse: A Journal of Research and Treatment, 25, $302-316$.

Smallbone, S., \& Wortley, R. (2000). Child sexual abuse in Queensland: Offender characteristics \& modus operandi. Queensland: Queensland Crime Commission and the Criminology Research Council.

Smid, W.J., Kamphuis, J.H., Wever, E.C., \& Van Beek, D.J. (2014). A comparison of the predictive properties of nine sex offender risk assessment instruments. Psychological - Assessment, 26, $691-703$.

Stephens, S., Seto, M.C., Goodwill, A.M., \& Cantor, J.M. (2016). The relationships between victim age, gender, and relationship polymorphism and sexual recidivism. Sexual

This article is protected by copyright. All rights reserved. 
Abuse: A Journal of Research and Treatment. Advance online publication.

Doi:10.1177/1079063216630983

Terry, K.J., \& Ackerman, A.R. (2009). A brief history of major sex offender laws. In R.G. Wright (Ed.), Sex offender laws: Failed policies, new directions (pp. 65 - 98). New York: Springer.

Tewksbury, R. (2005). Collateral consequences of sex offender registration. Journal of Contemporary Criminal Justice, 21, $67-81$.

Tewksbury, R., \& Lees, M.B. (2006). Perceptions of sex offender registration: Collateral consequences and community experiences. Sociological Spectrum, 26, 309 - 334.

Tewksbury, R., \& Lees, M.B. (2007). Perceptions of punishment: How registered sex offenders view registries. Crime \& Delinquency, 53, $380-407$.

Thomas, T. (2008). The sex offender 'register': A case study of function creep. The Howard Journal, 47, $227-237$.

Vess, J. (2008). Sex Offender Risk Assessment: Consideration of Human Rights in Community Protection Legislation. Legal and Criminological Psychology, 13, 245 - 256.

Vess, J. (2009). Fear and loathing in public policy: Ethical issues in laws for sex offenders. Aggression and Violent Behavior, 14, 264 - 272.

Vess, J., \& Eccleston, L. (2009). Extended supervision of sexual offenders in Australia and New Zealand: Differences in implementation across jurisdictions. Psychiatry, Psychology and Law, 16, $271-287$.

This article is protected by copyright. All rights reserved. 
Vess, J., Langskaill, B., Day, A., Powell, M., \& Graffam, J. (2011). A comparative analysis of Australian sex offender legislation for sex offender registries. Australian \& New Zealand Journal of Criminology, 44, 404-424.

Vess, J., \& Skelton, A. (2010). Sexual and violent recidivism by offender type and actuarial risk: Reoffending rates for rapists, child molesters and non-contact offenders.

Psychology, Crime and Law, 16, 541 - 554.

Wollert, R., Cramer, E., Waggoner, J., Skelton, A., \& Vess, J. (2010). Recent research (N = 9,305) underscores the importance of using age-stratified actuarial tables in sex offender risk assessments. Sexual Abuse: A Journal of Research and Treatment, 22, $471-490$.

Yang, M., Wong, S.C.P., \& Coid, J. (2010). The efficacy of violence prediction: A metaanalytic comparison of nine risk assessment tools. Psychological Bulletin, 136, 740 $\underline{767 .}$

Zgoba, K.M. (2004). Spin doctors and moral crusaders: The moral panic behind child safety legislation. Criminal Justice Studies, 17, 385 - 404.

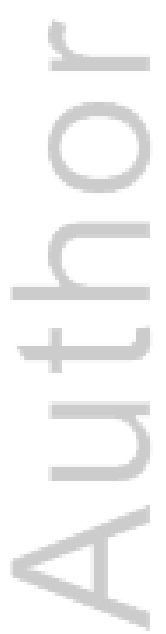

This article is protected by copyright. All rights reserved. 


\section{University Library}

\section{- M M N E R VA A gateway to Melbourne's research publications}

Minerva Access is the Institutional Repository of The University of Melbourne

Author/s:

Day, A;Darwinkel, E;Vess, J

Title:

The characteristics of registered sexual offenders in an Australian jurisdiction

Date:

2017-06-01

Citation:

Day, A., Darwinkel, E. \& Vess, J. (2017). The characteristics of registered sexual offenders in an Australian jurisdiction. JOURNAL OF INVESTIGATIVE PSYCHOLOGY AND OFFENDER PROFILING, 14 (2), pp.120-132. https://doi.org/10.1002/jip.1461.

Persistent Link:

http://hdl.handle.net/11343/291601 